\title{
ATTITUDES TOWARDS THE SCOPE OF GOVERNMENT: DO WE HAVE A GENERATION GAP?
}

Algis KRUPAVIČIUS, Faculty of Social Sciences, Vytautas Magnus University, K. Donelaičio g. 58, 44248, Kaunas, Lithuania. algis.krupavicius@vdu.lt (corresponding autor)

Ligita ŠARKUTE், Faculty of Political Sciences and Diplomacy, Vytautas Magnus University K. Donelaičio g. 58, 44248, Kaunas, Lithuania. ligita.sarkute@vdu.lt

Today an impact of government on citizens' daily life is bigger than ever before. The extent to which people support governmental actions is related with their support of the whole political system. The scope of government varies across different states as well as people's attitudes towards it also vary considerably. The scope of government, according Borre and Scarbrough (1998), is referred to both the range of government activity and the degree to which governments engage in activities, such as spending on services, taxing, regulating citizens and regulating their behaviour, providing resources for defence, improving the environment and sometimes doing nothing what concerns societal problems. Depending on the role of government in economy and social sphere we can distinguish how small or big the government is. The ISSP Role of Government module data provides a wide range of variables indicating people's attitudes towards different elements of governments' actions. Recent research, e. g. a study of Pew Research - The Generation Gap in American Politics (March, 2018) - shows the important difference in generational attitudes towards the scope of government. According to this study two younger USA generations, Millennials and Gen Xers, stand apart from the two older cohorts, Baby Boomers and Silents - especially Millennials (those, who were born in 1981 and later) have increasingly liberal outlook. Thus, the main question of this article - does the same generational divide might be observed in other countries and what are the main differences in generational attitudes towards the scope of government from the crossnational perspective?

Keywords: attitudes, beliefs, generations, political regimes, scope of government.

\section{INTRODUCTION}

In contemporary world an impact of governments on our daily lives is almost constantly increasing. The best illustration of this trend is an evolution of nation state from a night watchman or liberal state with very narrow concentration on maintaining law and order in $17^{\text {th }}$ century to welfare state with broad provisions of welfare for all citizens in the second half of $20^{\text {th }}$ century (Hague and Harrop, 2004). All this happens because of variety of complex economic, social, demographic and other causes ${ }^{1}$.

On the other side citizens support of the government is an important pillar of its' legitimacy. Moreover, the extent to which people support governmental actions is related with their support of the whole political system. All this requires of in-depth studies.

\section{CONCEPTS OF SCOPE OF GOVERNMENT AND GENERATIONS}

Government is a key concept in comparative political science and its current definition refers to all activities of steering within human groups and organizations. Borre and Goldsmith (1998) in a classical book "The Scope of Government" described the scope of government as "the range of government activity and the degree to which governments engage in activities which have an impact on people's daily lives".

The range of government, according Borre and Goldsmith (1998), is referred to the whole gamut of government activities, such as spending on services, taxing, regulating citizens and regulating their behaviour, providing for defence, improving the environment and sometimes doing nothing what concerns societal problems. By the degree, they meant "the intensity with which government pursues a particular activity" (Borre and Goldsmith 1998), for instance, more efforts by government to provide a comprehensive health care.

All individuals in different societies hold attitudes in relation to a wide diversity of topics. Attitudes are often defined as a set of beliefs organized around a specific object or situation (Knutsen, 2011). As Araujo (2011) pointed out attitudes eventually establish connections between one topic and another. But attitudes lie within individuals' minds; therefore, they are nonobservable, or latent, properties, and speak about attitudes, we need to build, analytically, the aspects of reality the existence of which we postulate (Araujo, 2011). The first and best-known attempts to measure attitudes employed projective tools, scales, attitudinal indices allowing inferences about latent structures through manifest observations and data. All these tools are based on the principle of a stimulus (a question) and a response (a verbal answer) that elicits some unobservable mental state. The idea

\footnotetext{
${ }^{1}$ See more on the growth of government activity in Goldsmith (1998).
}

Copyright (C) 2019 The Authors. Published by Vytautas Magnus University. This is an open-access article distributed under the terms of the Creative Commons Attribution License (CC-BY 4.0), which permits unrestricted use, distribution, and reproduction in any medium, provided the original author and source are credited. 
that attitudes can be measured by recording manifest verbal expressions from which they can be inferred had a significant impact on the development of the techniques of quantitative survey analysis (Araujo, 2011). The International Social Survey Programme (ISSP) module "Role of Government" represents quantitative survey of political attitudes and gives a wide range of variables indicating people's attitudes towards different elements of government actions.

Why should attitudes towards the scope of government are important to us? Firstly, governmental actions became highly important in our daily lives and citizens demands to governments are increasing as well. Secondly, with a spread of democracy citizens support of the government is becoming more visible and the extent to which people is backing government well correlates with their support of the whole political system. Thirdly, even though many citizens today hold stable political attitudes, including about the scope of government and do not change them easily, there is a general theoretical consensus that all attitudes can change. Here we might ask a question of Abramson and Inglehart (1992: 1) are the social/ political priorities of Western/ global publics changing? - it highly likely that with the International Social Survey Programme (ISSP) data we would be able to demonstrate that generational differences in attitudes towards the scope of government ${ }^{2}$ are not only important for Western publics, but it is globally relevant phenomenon.

According to Burnett (2010), the concept of generations is one which historically sought to address the fact of human existence and human self-understandings as collective and individual in the contexts of co-existence and relatedness which occurs in slices of time. It is a concept to which time and space relationships are integral. But from a perspective of three different approaches (Generation as social agency, Generation as inter-generational structure and Generational mapmaking ${ }^{3}$ ) in the contemporary development of the concept of generations, we tend to focus on generational map-making as these maps show representations of societies as consisting of a sequence of generations (Burnett, 2010).

The focus of this study is to analyze possible generational differences in attitudes towards a scope of government. Since a seminal project on the Beliefs in Government from the late 1980-s and early 1990-s, which for the first time charted radical changes in the relationship between citizens and the state in Western European democracies, became obvious that understanding of public attitudes about the scope of government is highly complex enterprise. Beliefs, according to Borre and Goldsmith (1998), are "about what the government should do, can do, or is actually doing".

Also, we need to think here about generational impacts as far as socialization of different age cohorts occurred in very different environments. Traditionalists, who been born in 1925-1946, might be named as a generation of crisis, i.e. Great Depression, World War II. Baby boomers from 1947 till 1961 is a post-war generation, which started with economic and social hardships, but ended with economic growth and serious social improvements. Generation X is a child of welfare state policies (which been moving from liberal to social democratic model) in many countries. And finally, Generation $\mathrm{Y}$, which socialized in the environment of relative material affluence and self-expression values are much more important to them in comparison to all previous generations. One more important observation is appropriate here that national governments expanded their activities and influence of societal life considerably across these generations.

In general, the analysis of the scope of government revealed a serious lack of comparative data. The ISSP surveys have cross-national data, but as far as differences between countries are large, macro analysis requires time-series data in order to find out specific factors about general differences towards the role of government.

Following the logic of Beliefs in Government project we developed four dimensions or groups of items based on the ISSP "Role of Government V" survey to measure attitudes on the scope of government: a) government responsibility, b) policy and regulation, c) policy change, and d) perceived government performance (Table 1).

Table 1. Dimensions of the scope of government

\begin{tabular}{|c|l|}
\hline Groups of items & \multicolumn{1}{c|}{ Questions } \\
\hline $1 . \quad$ Government responsibility & It should or should not be the government's responsibility to ... \\
& Q7a. provide a job for everyone who wants one \\
& Q7b control prices \\
& Q7c. provide health care for the sick \\
& Q7g. reduce income differences between \\
& Q7k. promote equality between men/ women \\
\hline $2 . \quad$ Policy and regulation & You are in favour of or against: \\
& Q5a. Cuts in government spending \\
& Q5c. Less government regulation of business \\
& It should or should not be the government's responsibility to ... \\
& Q7j. impose strict laws to make industry do less damage to the environment \\
\hline $3 . \quad$ Policy change & Whether you would like to see more or less government spending in: \\
& Q6b. Government should spend money: health \\
& Q6c. Government should spend money: police and law enforcement \\
& Q6d. Government should spend money: education \\
& Q6f. Government should spend money: old age pensions \\
\hline $4 . \quad$ Perceived government & How successful the government in the country is nowadays in: \\
& Q23a. Government successful: providing health care for sick \\
& Q23b. Government successful: providing living standard for old \\
& Q23c. Government successful: dealing with threats to security \\
\hline
\end{tabular}

\footnotetext{
${ }^{2}$ We are not analyzing values as values are sometimes contrasted with attitudes, which are often defined as a set of beliefs organized around a specific object or situation- see more in Knutsen (2011).

${ }^{3}$ See more in Burnett (2010, p. 49).
} 
Generational theories argue that the context of one's socialization is the most important factor for understanding differences in values as well as beliefs and attitudes (Grasso et al., 2018, p. 9). In order to study generational divide on political attitudes first we need to make a choice on classification of age cohorts. But a typology of generations is extremely complicated issue. Despite mountains of academic literature on generations there is no consensus among sociologists, demographers, psychologists and so on typology of generations. The naming of generations in this study stem from well- known William Strauss and Neil House book called Generations (1991).

Assignment of age ranges was developed using several studies. The periods of generational socializations are divided following Inglehart (1990), Bartels and Jackman (2014). Several studies helped to establish generational borders, including Grasso (2016), Burnett (2010), Heath and Park (1997), Miller (2011), Dimock (2018), Becker (1990) and others. Finally, we ended up with four generational groups, i.e. Traditionalists and Silents, Baby boomers, Generation X and Generation Y (see Table 2). Of course, this cross-national typology misses some key differences in formative experiences between members of the same 'generations' in different countries (Grasso et al. 2018: 41), but it is applicable for our small-N analysis.

Table 2. Generations and age ranges

\begin{tabular}{|l|c|c|}
\hline & Year of birth & Age (in 2016) \\
\hline Traditionalists and Silents & $1925-1946$ & $70-91$ \\
\hline Baby boomers & $1947-1961$ & $55-69$ \\
\hline Generation X & $1962-1981$ & $35-56$ \\
\hline Generation Y or Millennials & $1982-2001$ & $15-34$ \\
\hline
\end{tabular}

\section{DATA COLLECTION METHOD AND PROCEDURE}

At the very beginning it needs to be noted that the ISSP module "Role of Government" was the first study among 34 modules carried out by this organization in a period from 1985 to 2018 . The "Role of Government" was implemented as many as five times in 1985, 1990, 1996, 2006, 2016.

The data of this module gives a wide range of variables indicating people's attitudes towards different elements of governments' actions including a possibility to study them from a generational perspective. Also the 2016 ISSP "Role of Government V" data allows us to detect intergenerational attitudinal differences on the scope of government crossnationally. Analysis of the generational differences on the scope of government was primarily based on descriptive statistics along with few elements of inferential statistics.

\section{RESULTS AND DISCUSSION}

Attitudinal differences towards the scope of government between countries may develop due to long-term factors as diverse historical transformations, different levels of social and economic well-being, variety of political and cultural traditions. Also, country-specific short-term factors such as development - shaping events, economic or/ and social crises, change of institutional rules of the game are important for differences in generational constellations of attitudes cross-nationally.

In the late 1980-s and 1990-s there was a general assumption, especially among researchers from Anglo-Saxonian countries, that demands for government intervention are decreasing as countries becoming wealthier. For instance, Inglehart in his book on Culture Shift in Advanced Industrial Society (1990) noted there is the trend in economically advanced societies that people tend to oppose further expansion of welfare then society reaches a certain personal income level.

However, in recent decades again we see powerful trends toward greater wealth and income inequality in the Western countries and globally, which is based on the rise of global flows of labor, goods, peoples, and capital, shrinking welfare safety-net, and liberal austerity policies ${ }^{4}$. Here we might assume that the economic insecurity thesis may play again a positive role for a comeback of broader government intervention on attitudinal level and on a global scale. Still we need to have consistent evidence here, but we may rise a hypothesis that generations affected by the economic insecurity on a higher scale may be more pro-statist or pro-interventionist compared to those who are less experiencing economic troubles.

Differences in attitudes towards the scope of government also may be related to the values which prevail in different generations. The older generations are more materialist and emphasize more economic government intervention, also law and order functions. The middle generations, especially Baby boomers, look more up to welfare policies as youngest generations are much more post-materialist and self-expressionist and emphasize regulatory functions of state.

Now let's back to our four dimensions of the scope of government and try to find out an empirical evidence about relations between generational attitudes on the role of government in the context of different political regimes.

The pattern of generational differences in attitudes on the role and scope of government varies across issues. What descriptive statistics tell us about perceptions of government responsibility? But before to go to the 2016 ISSP survey data, let's note that recent Pew Research Center study 'The Generation Gap in America Politics" showed that in the US over the last several decades a clear generational divide has been evident in the scope of government: younger generations more likely than those in older generations expressed a preference for a bigger government with more services (Pew Research Center 2018). Are these trends observed in the 2016 ISSP data and cross-nationally?

\footnotetext{
${ }^{4}$ See more in Piketty (2014) and Hacker (2006).
} 
Government responsibility. The aggregated ISSP data on generational attitudes towards the role of government shows that neither in full democracies, nor in flawed democracies and in hybrid regimes observed trends do not follow exactly the same pattern as in the US case. The most similar generational attitudes towards government responsibility to the US can be observed in hybrid regimes - Baby Boomers outperform all other generations in preferring smaller government. Big government in hybrid regimes is preferred mostly by Traditionalists (except dimension on gender equality, where Generation Y, or Millennials, are leading in support). Another trend detected in hybrid regimes is that acceptance of bigger government grows in younger generations compared with Baby Boomers (except government responsibility to control prices). So, it can be concluded that Gen Xers and Millennials are more likely than Baby Boomers think that government should take active role in doing more for the needy and underprivileged groups. Millennials are usually more likely than older generations to prefer bigger government along the dimension of government responsibility.

The opposite trend on the government responsibility dimension is observed in flawed democracies - an acceptance of bigger government decreases in younger generations compared the older ones (with one exception of government responsibility to promote gender equality. But it also worth to mention that differences across generations between the oldest and the youngest generations in flawed democracies are not as big as in hybrid regimes. The intergenerational differences in perceptions of government responsibilities are even smaller in full democracies and fluctuate around few percent. On some dimensions of perceived government responsibilities younger generations in full democracies prefer smaller government than older generations (for example controlling prices or reducing income differences), but on rest of dimensions there are no significant differences.

Policy and regulation. Generational attitudes on government policy and regulation do not differ much. In hybrid regimes we can see that smaller government, i.e. less government spending, is mostly preferred by Traditionalists, or the oldest generation. Baby Boomers are less likely to think that government spending should be reduced, but in the younger generations acceptance of this idea slightly grows up. The same situation in the hybrid regimes is also with perceptions of government regulation of business. Slightly opposite situation is with attitudes towards government responsibility to impose strict laws to make industry do less damage to the environment - Traditionalists here are mostly in favor of it, along with the youngest generation, i.e. Millennials, but Baby Boomers and Gen Xers are less inclined to accept this idea.

In flawed democracies generational differences are also not very significant and they are even marginal when we consider regulating industry in order to protect environment. The same trends are seen in the case for full democracies. Bigger differences can only be observed in perceptions of government's role in regulating business - the oldest generation is mostly in favour of smaller government and less regulation as and the youngest one is relatively more pro-regulation.

Across different generations and different political regimes there is broad and strong consensus about government responsibility, i.e. "definitely should" or "probably should", to impose strict laws to make industry do less damage to the environment.

Inferential statistics and two step cluster analysis ${ }^{5}$ allowed us to extract three government regulation clusters: less regulation, more regulation and status quo regulation. Chi-square analysis showed that statistically significant dependence between government regulation clusters and generations exist, but it is low (Cramer's V $=0,036$, what means that only \pm $4 \%$ statistically significant difference between acceptance or non-acceptance of government regulation could be explained by generational differences; see Table 3). Still it allows to say that acceptance of less or status quo government regulation increases in youngest generation compared to all the rest generations.

Table 3. Government regulation and generational attitudes

\begin{tabular}{|c|c|c|c|c|}
\hline \multirow{2}{*}{ Generations } & \multicolumn{3}{|c|}{ Cluster } & \multirow{2}{*}{$\begin{array}{c}\text { Chi-square } \\
\text { (Cramer's V) }\end{array}$} \\
\cline { 2 - 5 } & Less government regulation & $\begin{array}{c}\text { More government } \\
\text { regulation }\end{array}$ & $\begin{array}{c}\text { Status quo } \\
\text { government } \\
\text { regulation }\end{array}$ & $83,991 * * *$ \\
& $36,6 \%$ & $33,4 \%$ & $30,0 \%$ & $\left(0,036^{* * *}\right)$ \\
\hline Generation Y & $41,8 \%$ & $30,8 \%$ & $27,4 \%$ & \\
\hline Generation X & $42,3 \%$ & $31,5 \%$ & $26,2 \%$ & \\
\hline Baby Boomers & $40,9 \%$ & $32,8 \%$ & & \\
\hline Traditionalists & & &
\end{tabular}

Data source: ISSP Research Group (2018).

Policy change. On the dimension of policy changes, which is operationalized as government spending, intergenerational differences are not very large, but in some policy domains they are higher compared to others. This mainly concerns spending on education and old age pensions. Preferences of much higher government spending on education are more important for young people and the youngest generation compared with older ones. And, on the opposite, older generations more likely than those in younger generations tend to express their preference for higher spending on old age pensions.

When we look on public spending on police and law enforcement it could be observed that in hybrid regimes Millennials outperform all other generations in preferring bigger government in the sense of much higher spending in this policy domain. In flawed democracies generational differences on higher public spending on police and law enforcement are insignificant, but in full democracies we can clearly see that the preference of higher spending in this domain decreases in the youngest generation. People's desire that government should raise the spending on health is quite similar in all

\footnotetext{
${ }^{5}$ For two step cluster analysis was used Schwartz's Bayesian Criterion.
} 
generations both in flawed democracies and in full democracies, but in hybrid regimes Traditionalists prefer higher spending on health compared the youngest generation.

Perceived government performance. Generational differences in perceived government performance are rather small. The most obvious generational differences in hybrid regimes are seen in evaluating of government success in dealing the threats of security - Traditionalists here are more than twice less keen to think that government is very or quite successful dealing in this public policy domain. Significant differences between generations in hybrid regimes are also observed in evaluating of how successful government is in providing living standard for old - Baby Boomers and Gen Xers see government as very or quite successful around twice better in comparison to Traditionalists, but in the youngest generation - Millennials - these numbers decrease a bit again. In flawed and full democracies intergenerational differences in evaluating government performance in all analysed policy domains are not significant.

\section{CONCLUSIONS}

If to draw main conclusion from findings of our study, it would be the following: generational differences in attitudes towards the scope of government are important for Western publics, and it is globally relevant phenomenon. As the 2016 ISSP data analysis demonstrates intergenerational differences on the scope of government are not so large as we may initially assumed. Instead of intergenerational differences we may observe, but with some important exceptions, relatively broad generational consensus on the role of government. Still, a generational divide has been evident in views on the role of government, with those in younger generations more likely than those in older generations to show a preference for a bigger government with more social services and welfare safety net A broad intergenerational consensus was observed on the need of active government role in expanding of health care coverage.

Our data-driven study after employing a multiple correspondence analysis is showing that intergenerational differences are important and are larger on the level of different political regimes. The strongest statistical associations are seen in full democracies where respondents evaluate government activities as successful and they are in favour of more spending on education and health care. Meanwhile, preferences in flawed democracies fall for moderate spending by government and moderate government regulation. Respondents from hybrid regimes tend to evaluate performance of government as less successful, but they are for higher public spending especially in social policy domain.

Acknowledgement. This research was funded by a grant (No. S-MIP-17-120) from the Research Council of Lithuania.

\section{REFERENCES}

1. Abramson P. R., Inglehart R. 1992. Generational Replacement and Value Change in Eight West European Societies. British Journal of Political Science, Vol. 22, Iss. 2, pp. 183-228. https://doi.org/10.1017/S0007123400006335

2. Araujo M. M. 2011. Attitudes, Political. Pp. 96-101 in International Encyclopedia of Political Science, edited by B. Badie, D. Berg-Schlosser, and L. Morlino. SAGE, Thousand Oaks, CA. SAGE Reference Online. Web. 30 Jan. 2012.

3. Bartels L. M., Jackman S. 2014. A Generational Model of Political Learning. Electoral Studies, Vol. 33, pp. 7-18. https://doi.org/10.1016/j.electstud.2013.06.004

4. Becker H. A. 1990. Dynamics of Life Histories and Generations Research. Life Histories and Generations. ISOR, Utrecht.

5. Burnett J. 2010. Generations: The Time Machine in Theory and Practice. Routledge, New York.

6. Borre O., Goldsmit, M. 1998. The Scope of Government. Pp. 1-22 in The Scope of Government, edited by O. Borre and E. Scarbrough. Oxford University Press, Oxford. https://doi.org/10.1093/0198294743.003.0001

7. Dimock M. 2018. Defining Generations: Where Millennials End and Post-Millennials Begin. Pew Research Center. (http://www.pewresearch.org/fact-tank/2018/03/01/defining-generations-where-millennials-end-and-post-millennials-begin/).

8. Goldsmith M. 1998. The Growth of Government. Pp. 25-54 in The Scope of Government, edited by O. Borre and E. Scarbrough. Oxford University Press, Oxford.

9. Grasso M. T. 2016. Generations, Political Participation and Social Change in Western Europe. Routledge, New York. https://doi.org/10.4324/9781315684031

10. Grasso M. T, Farrall S., Gray E., Hay C., Jennings W. 2018. Socialization and Generational Political Trajectories: An Age, Period and Cohort Analysis of Political Participation in Britain. Journal of Elections, Public Opinion and Parties, Vol. 29, Iss. 2, pp. 199-221. doi: 10.1080/17457289.2018.1476359.

11. Hacker J. 2006. The Great Risk Shift: The New Economic Insecurity and the Decline of the American Dream. Oxford University Press, New York.

12. Hague R., Harrop, M. 2004. Comparative Government and Politics. $6^{\text {th }}$ ed. Palgrave, New York.

13. Heath A., Park, A. 1997. Thatcher's Children? Pp. 1-22 in British Social Attitudes: The 14th Report, The End of Conservative Values?, edited by R. Jowell. Sage, London.

14. Inglehart R. 1990. Culture Shift in Advanced Industrial Society. Princeton University Press, Princeton. https://doi.org/10.1515/9780691186740

15. ISSP Research Group. 2018. International Social Survey Programme: Role of Government V - ISSP 2016. GESIS Data Archive, Cologne. ZA6900 Data file Version 1.0.0, doi: 10.4232/1.13052.

16. Knutsen O. 2011. Values. Pp. 2692-2698 in International Encyclopedia of Political Science, edited by B. Badie, D. Berg-Schlosser, and L. Morlino. SAGE, Thousand Oaks, CA. SAGE Reference Online. 
17. Miller J. 2011. The Generation X Report: Active, Balanced, and Happy: these Young Americans are not Bowling Alone. Longitudinal Study of American Youth - University of Michigan. Retrieved August 13,2018 (http://lsay.org/GenX_Rept_Iss1.pdf).

18. Pew Research Center. 2018. The Generation Gap in American Politics. (http://www.people-press.org/2018/03/01/the-generationgap-in-american-politics/).

19. Piketty T. 2014. Capital. Bellnap Press, Cambridge, MA.

20. Strauss W. House, N. 1991. Generations: The History of America's Future, 1584 to 2069. Morrow, New York. 